\title{
Direito Ambiental Global: Limites e Possibilidades de Implementação*
}

\author{
Global Environmental Law: Limits and Possibilities of Implementation \\ Derecho Ambiental Clobal: Limitesy posibilidades de Implementación
}

DOI: https://doi.org/10.21803/pensam.v12i24.313

Maria Claudia da Silva Antunes de Souza https://orcid.org/0000-0002-8118-1071

Charles Alexandre Souza Armada https://orcid.org/0000-0003-2921-6182

\section{¿Cómo citar este artículo?}

Da silva Antunes, M. \& Souza, C. (2019). Direito Ambiental Global: Limites e Possibilidades de Implementação. Pensamiento Americano, 12(24) 117-129.

DOI: https://doi.org/10.21803/pensam.v12i24.313

\section{Resumo}

O processo de esgotamento dos recursos naturais planetários permanece evidenteapesar dasiniciativas da comunidade internacional e científica. Nesse sentido, com base em pesquisa bibliográfica e através do método indutivo, o objetivo do presente artigo é estimular reflexões a respeito de um Direito Ambiental Global como alternativa para reverter o quadro atual de degradação ambiental global. Para atingir o objetivo proposto, inicialmente é discutida a necessidade de um Direito Ambiental Global; em seguida, discutem-se as dificuldades e possibilidades de implementação de um Direito Ambiental de âmbito global. Depreendeu-se da pesquisa efetuada que a confluência das ações, particularmente aquelas envolvendo o Direito Internacional, voltadas, por sua vez, para a preservação do meio ambiente planetário denotam a possibilidade de consolidação e implementação de um Direito Global versando sobre a temática ambiental. A metodologia utilizada para o desenvolvimento da pesquisa foi o método indutivo.

Palavras-Chave: Direito Ambiental Global. Meio Ambiente. Governança Ambiental Global. Sustentabilidade. Desenvolvimento Sustentável.

\begin{abstract}
The process of depletion of planetary natural resources remains evident despite the initiatives of the international and scientific community. In this sense, based on bibliographic research and through the inductive method, the aim of this article is to stimulate reflections on a Global Environmental Law as an alternative to reverse the current global environmental degradation. In order to reach the proposed objective, initially the research discusses the need for a Global Environmental Law; then, discusses the difficulties and possibilities of stablishing an Environmental Law of global scope. It emerged from the research carried out that the confluence of actions, particularly those involving international law, aimed at the preservation of the planetary environment, indicates the possibility of consolidation and implementation of a Global Law dealing with environmental issues. The methodology used for the development of the research was the inductive method.
\end{abstract}

Key words: Global Environmental Law. Environment. Global Environmental Governance. Sustainability. Sustainable Development. 


\section{Resumo}

El proceso de agotamiento de los recursos naturales del planeta permanece evidente a respeto de las iniciativas de la comunidad científica internacional. En este sentido, basado en la investigación bibliográfica y a través del método inductivo, el objetivo de este artículo es estimular reflexiones sobre el Derecho Ambiental Global como una alternativa reversa a la degradación ambiental global. Para dar seguimiento a la investigación propuesta, inicialmente la investigación caminó en el sentido de la necesidad de una Ley Ambiental Global; en seguida se dispuso a debatir las dificultades y posibilidades de establecerse una Ley Ambiental Global como objetivo. Este objeto surgió a partir de investigaciones que apuntaron la confluencia de acciones, particularmente aquellas involucrando derecho internacional, direccionada a la preservación del medio-ambiente indicando la posibilidad de consolidación e implementación de una Ley Ambiental Global que responda a las cuestiones ambientales. La metodología utilizada fue el método inductivo.

Palabras- clave: Derecho Ambiental Global. Medio-ambiente. Governança Ambiental Global. Sostenibilidad. Desarrollo sostenible.

\section{Perfil}

Mestre em Ciência Jurídica pela Universidade do Vale do Itajaí - UNIVALI. Professora Permanente no Programa de Pós-Graduação Stricto Sensu em Ciência Jurídica, nos cursos de Doutorado e Mestrado, e na Graduação no Curso de Direito, ambos da Universidade do Vale do Itajaí - UNIVALI. Coordenadora do Grupo de Pesquisa "Direito Ambiental, Transnacionalidade e Sustentabilidade" cadastrado ao CNPq/EDATS/UNIVALI. Coordenadora do Projeto de pesquisa aprovado no CNPq intitulado: "Análise comparada dos limites e das possibilidades da avaliação ambiental estratégica e sua efetivação com vistas a contribuir para uma melhor gestão ambiental da atividade portuária no Brasil e na Espanha". E-mail: mclaudia@univali.br http://lattes.cnpq.br/2095171218854616

\section{Perfil}

Doutor e Mestre em Ciência Jurídica pela Universidade do Vale do Itajaí

- UNIVALI. Professor no Programa de Pós-Graduação Lato Sensu no Curso de Relações Internacionais e na Graduação dos Cursos de Direito e Relações Internacionais da Universidade do Vale do Itajaí - UNIVALI. Coordenador do Grupo de Estudos em Direito Internacional Ambiental e Governança Global e em Meio Ambiente e Sustentabilidade, ambos pela Universidade do Vale do Itajaí - UNIVALI. Coordenador do Projeto de Extensão "Laboratório de Cidadania e Sustentabilidade". E-mail: charlesarmada@hotmail.com http://lattes.cnpq.br/7188615625208159

\section{Maria Claudia da Silva Antunes de Souza}

Doutora e Mestre em Derecho Ambiental y de la Sostenibilidad

\section{Charles Alexandre Souza}

\section{Armada}

Doutor e Mestre em Derecho Ambiental y de la Sostenibilidad 


\section{Introdução}

O presente artigo possui como tema principal a análise e discussão de um Direito Ambiental Global no sentido de uma alternativa para reverter o quadro atual de degradação ambiental global.

Diversos relatórios de organismos internacionais, bem como informes científicos de autores renomados, vêm sendo divulgados nas últimas décadas dando conta do insustentável processo de exploração dos recursos naturais do planeta.

A despeito da gravidade da situação ambiental, os interesses particulares vêm prevalecendo na tomada de decisões da comunidade internacional. A dicotomia existente entre a atividade econômica e a preservação dos recursos naturais reflete, na verdade, as disparidades históricas envolvendo as Governanças Globais que tratam das duas categorias.

O objetivo da pesquisa é contribuir para a discussão de um Direito Ambiental Global no sentido de uma alternativa para reverter o quadro atual de degradação ambiental global.

Por este motivo, o problema de pesquisa é como equalizar a celeuma advinda da uniformização do ordenamento jurídico global e o quadro atual de degradação ambiental no planeta? E, ainda, qual o caminho para a implementação de um Direito Ambiental Global?

Para atingir o objetivo proposto, a pesquisa foi dividida em três momentos: na primeira parte analisa-se a necessidade de um Direito Ambiental Global; em seguida, a pesquisa discute as dificuldades inerentes à implementação de um Direito Ambiental com a abrangência proposta; finalmente, na terceira parte do trabalho, analisam-se as possibilidades de implementação de um Direito Ambiental de âmbito global.

A discussão promovida pelo presente artigo justifica-se, portanto, pela necessidade de se teorizar o novo papel que o Direito, particularmente o Direito Ambiental, pode e deve ter num planeta que busca a Sustentabilidade.

A pesquisa utilizou-se do método indutivo e sua operacionalização contou com as técnicas do referente, conceitos operacionais e fichamento.

\section{Da Necessidade de um Direito Ambiental Global}

A lógica capitalista privilegia o lucro e sua acumulação. $\bigcirc$ mundo tem exercitado e aprimorado essa lógica ao longo dos últimos dois séculos e, principalmente após a Segunda Guerra Mundial, promovido uma ligação tida como absolutamente necessária entre o modus operandi capitalista e o desenvolvimento econômico de povos e nações. $O$ fim da Segunda Guerra determinou o surgimento de uma governança do desenvolvimento que, ao longo dos últimos 70 anos, consolidou o desenvolvimento econômico como objetivo último dos países. Paralelamente, o mesmo período evidenciou a incapacidade de conciliação entre esse mesmo desenvolvimento econômico e a necessidade de preservação da qualidade ambiental planetária.

O respeito ao meio ambiente implica respeitar as gerações futuras, conforme definição apresentada pelo Relatório Brundtland para a expressão 'Desenvolvimento Sustentável', no sentido de ações solidárias em relação ao planeta que será deixado para as gerações que estão por vir. 
Contudo, além disso, significa também entender e respeitar alguns limites planetários que já estão sendo ultrapassados. Em estudo científico desenvolvido pelo Stockholm Resilience Centre (2018), foram estabelecidos alguns limites ambientais seguros dentro dos quais a humanidade pode se desenvolver sem que os impactos causados ao meio ambiente sejam irreversíveis, a saber: perda da biodiversidade, mudanças climáticas, ciclos biogeoquímicos, abusos no uso da terra, acidificação dos oceanos, mudanças no uso da água, degradação da camada de ozônio, carregamento de aerossóis para a atmosfera e poluição química.

Em estudo recentemente publicado pela revista Science, quatro dos nove limites já foram ultrapassados: a perda de biodiversidade, as mudanças climáticas, as alterações do ciclo do nitrogênio e os abusos no uso da terra (Steffen, Richardson, Rockström, CorneII, Fetzer, Bennett, Biggs, Carpenter \& Vries, 2015).

A proposta do conceito dos limites ambientais é reconectar o desenvolvimento econômico e social com a biosfera em uma abordagem preventiva para o desenvolvimento sustentável. Ao mesmo tempo, serve de alerta para o comportamento progressivo de deterioração do meio ambiente global e suas consequências para o ser humano. Finalmente, os limites ambientais (já ultrapassados ou em vias de o serem) também dão conta da incapacidade dos Estados nacionais para fazer frente a estes desafios.

Especificamente no que se refere ao limite ultrapassado pelas emissões de gases de efeito estufa e que, como consequência, determina o processo em curso de mudança climática global, a limitação dos Estados na- cionais é mais do que evidente. A luta contra o aquecimento global, inaugurada em 1992 quando da criação da Convenção-Quadro das Nações Unidas sobre Mudança do Clima (UNFCCC, na sigla em inglês) completa $1 / 4$ de século sem ter trazido resultados práticos, apesar dos riscos que o aumento da temperatura no planeta pode determinar para todos os países, indistintamente.

O aquecimento global verificado é perturbador tendo em vista a continuidade desse processo e os danos estimados. Tratando do tema, Landa, Ávila e Hernández (2010) alertam que:

Nos últimos 100 anos o nível médio do mar subiu cerca de $20 \mathrm{~cm}$, mais ou menos 3,1 $\mathrm{mm}$ ao ano desde 1993. Por exemplo, com um aumento do nível do mar perto de meio metro $(50 \mathrm{~cm})$ na costa de Tabasco, no México [...], o mar inundaria $50 \mathrm{~km}$ terra adentro. Isto também significa que algumas ilhas do planeta podem ser completamente inundadas em algumas estações do ano, e outras definitivamente desaparecer em médio prazo, como é o caso de Tuvalu, uma ilha perto da Austrália ${ }^{1}$ (p.34, tradução nossa).

Não apenas os pequenos países-ilhas, também as pessoas pobres estão menos preparadas a responder a qualquer mudança, a qualquer desafio ou alteração climática. Segundo Nobre (2008), a situação em que estes países se encontram evidencia a Injustiça Climática:

São os países que mais dependem dos recursos naturais e o impacto é maior nos países subtropicais e nas regiões secas, que é onde está a pobreza do mun-

En los últimos 100 años el nivel medio del mar se ha incrementado cerca de $20 \mathrm{~cm}$, más o menos $3.1 \mathrm{~mm}$ al año desde 1993 . Por ejemplo, con un incremento del nivel del mar cercano a medio metro $(50 \mathrm{~cm})$ en la costa de Tabasco en México [...], el mar inundaría $50 \mathrm{~km}$ tierra adentro. Esto también significa que algunas islas del planeta pueden quedar totalmente inundadas en algunas estaciones del año, y otras definitivamente desaparecerán en el mediano plazo, como es el caso de Tuvalú, una isla cerca de Australia.

Pensamiento Americano Vol. 12 - No. 24 · $2019 \cdot$ Julio - Diciembre · Corporación Universitaria Americana • Barranquilla, Colombia • ISSN: $2027-2448$ http://publicaciones.americana.edu.co/index.php/pensamientoamericano/index 
do. Essa é uma injustiça climática. Então os países do hemisfério norte emitem mais, mas os impactos serão maiores na região subtropical e nas regiões semi-áridas do planeta, pelo menos, neste século (p.402).

De fato, as nações pobres ou aquelas ainda em desenvolvimento serão as que mais sofrerão com os impactos decorrentes do aquecimento planetário. Frise-se que essa situação já vem sendo verificada tendo em vista os impactos determinados pelos chamados eventos extremos, diretamente relacionados com as mudanças climáticas globais.

Além da incapacidade (ou impossibilidade) dos Estados nacionais em lidar com os novos desafios impostos pelo próprio ser humano, há ainda outro fator relevante que inviabiliza o tratamento conjunto destas questões.

Não há uma uniformidade de ações e nem de interesses, mesmo em questões já pacificadas cientificamente, como é o caso da necessidade de limitação das emissões de gases de efeito estufa, por exemplo. É nesse sentido que Forst (2002), aponta que "em uma complexa rede de poderes, várias agências influenciam as ações de outros para que alguns deles lucrem, enquanto outros - coletivos ou pessoas - lucrem muito pouco ou não lucrem nada" (p.33, tradução nossa) ${ }^{2}$.

O tema envolve não apenas questões nacionais, mas, sobretudo, questões relacionadas com o Direito Internacional e categorias importantes como Soberania, Justiça Ambiental e Governança Global.

O tema também suscita exercitar um Dire- ito Ambiental que possa atuar globalmente. Nesse sentido, aproximando o tema da luta contra as mudanças climáticas com um Direito com características globais, Hautereau-Boutonnet (2017) apresenta: "Isso resultaria em um Direito Global, ou seja, um direito criado por e para seus destinatários (não-estatais) em uma área legal ainda desocupada por leis climáticas nacionais e internacionais, apropriadamente reguladas por padrões climáticos globais (cláusulas contratuais)" (p.31, tradução nossa) 3 .

Tendo em vista a gama de problemas que, em última análise, coloca em risco a continuidade do ser humano no planeta urge, portanto, pensar um Direito que ultrapasse as limitações impostas pelas fronteiras soberanas dos Estados nacionais e, ao mesmo tempo, supere as limitações de organismos internacionais e do Direito Internacional na resolução efetiva dos problemas que a Governança Global não tem conseguido obter êxito.

Valendo-se da definição promovida por Balbino (2017), o Direito Ambiental Global seria:

[...] o conjunto de princípios jurídicos desenvolvidos por sistemas regulatórios ambientais nacionais, internacionais e transnacionais, para a proteção do meio ambiente, é influenciado e influencia uma gama de atores, inclusive, a comunidade e as partes interessadas na proteção ambiental global (p.80).

Percival (2011), por sua vez, assim define o Direito Ambiental Global: "O conteúdo do Direito Ambiental Global é o conjunto comum de princípios legais desenvolvidos por sistemas nacionais, internacionais e transnacionais de

2 in a complex network of powers several agencies influence the actions of others so that a number of them profit, whereas others - collectives or persons - profit very little or not at all.

3 Il en découlerait un droit global, à savoir un droit créé par et pour ses destinataires (non étatiques) dans un espace juridique encore inoccupé par le droit climatique national et international, régulé opportunément par des normes climatiques globales (clauses contractuelles).

Pensamiento Americano Vol. 12 - No. 24·2019 • Julio - Diciembre · Corporación Universitaria Americana • Barranquilla, Colombia • ISSN: 2027-2448 http://publicaciones.americana.edu.co/index.php/pensamientoamericano/index 
regulamentação ambiental. Inclui valores substantivos, princípios e abordagens processuais" (p.623, tradução nossa) ${ }^{4}$.

Direito Ambiental é o candidato natural para uma demanda dessa envergadura não apenas pelos limites já ultrapassados ou pelos riscos dos impactos decorrentes, conforme já assinalado, mas, principalmente pelo fato de estar voltado para um propósito comum a todos os seres humanos: a manutenção da vida no planeta.

O Direito Ambiental Global, conforme proposto no presente estudo, é designado por alguns autores como Direito Planetário:

Pensar a sustentabilidade jurídica nos exige pensar o direito em um outro marco que não o do Estado Nação. Propomos algo aparentemente simples, mas que envolve ações complexas, onde a territorialidade possa dar base a uma nova soberania de todo o planeta, onde as fronteiras sejam dos lugares que tem vida, onde estabeleçamos um novo marco de tutela jurisdicional na biosfera como fronteira jurídica de um novo direito sustentável. Na falta de uma melhor denominação chamaremos de Direito Planetário (Ruschel \& Portanova, 2015, p.42).

Há, também, alguns autores que desenvolvem o conceito do Geodireito (Armada \& Vieira, 2015) ou do Direito Global (Staffen, 2016) com as mesmas linhas epistemológicas dos conceitos já apresentados. Independentemente da nomenclatura utilizada, tendo em vista a confluência de propósitos e conceitos, o Direito Ambiental Global, ou Direito Global, ou Direito Planetário, ou Geodireito, pensa o meio ambiente sem as amarras e dificulda- des determinadas pelas fronteiras imaginadas pelo ser humano.

Indo além, um Direito Ambiental pensado no âmbito global tem o condão de aliar a perspectiva da solidariedade, entre os povos e entre diferentes gerações, com a necessidade de uma atuação igualitária privilegiando um bem que é comum a todos os povos: o meio ambiente.

\section{Das Dificuldades de Implementação de um Direito Ambiental Global}

Analisando o empenho do Direito Internacional para conter o aquecimento do planeta, Waeyenberge considera o Protocolo de Quioto e, mais especificamente, os mercados de carbono, como um verdadeiro 'caso com vocação global', no sentido de permitir uma análise do comportamento dos diferentes atores na busca de soluções para um problema comum e, ao mesmo tempo, observa a incapacidade de atuação do Estado nacional para lidar com problemas de abrangência global. Segundo Waeyenberge (2017): "Com efeito, tanto o assunto 'meio-ambiente' quanto os instrumentos utilizados na sua regulação nos convidam a repensar o direito sob a ótica de lentes teóricas diferentes daquelas herdadas dos Estados-nação" (p.19).

De fato, os resultados obtidos pelo Protocolo de Quioto estão longe de serem considerados satisfatórios. As emissões de gases de efeito estufa, objeto precípuo do Protocolo, continuaram aumentando em praticamente todas as regiões do planeta.

Apesar do fracasso determinado pelo Protocolo de Quioto em termos de limitação das emissões de gases de efeito estufa, o apontamento de sua vocação global é pertinente

4 Global environmental law's content is the common set of legal principles developed by national, international, and transnational environmental regulatory systems. It includes substantive values, principles, and procedural approaches.

Pensamiento Americano Vol. 12 - No. 24 · 2019 • Julio - Diciembre • Corporación Universitaria Americana • Barranquilla, Colombia · ISSN: 2027-2448 $\mathrm{http} / / /$ publicaciones.americana.edu.co/index.php/pensamientoamericano/index 
tendo em vista que o objeto final pretendido pelo Protocolo estava diretamente relacionado ao meio ambiente planetário.

Os interesses particulares dos Estados muitas vezes se sobrepõem aos interesses coletivos dificultando a cooperação entre os Estados e muitas vezes inviabilizando a obtenção de resultados satisfatórios. Esse foi o caso, em grande medida, do insucesso do Protocolo de Quioto, e também explica a saída dos Estados Unidos do Acordo de Paris.

Como o meio ambiente planetário não respeita as fronteiras imaginadas pelo ser humano, as ações egoístas em relação ao clima global afetam todos os demais países, mesmo aqueles profundamente envolvidos com a temática destacada.

Além das limitações envolvendo a capacidade de cooperação entre os Estados nacionais no âmbito do Direito Internacional Público, conforme exemplos já destacados e relacionados com o aquecimento planetário e suas consequências na dinâmica climática do planeta, o próprio Estado nacional pode perceber dificuldades internas para o desenvolvimento da proteção ao meio ambiente.

Portanto, as dificuldades para a configuração e efetivação de um Direito Ambiental Global envolvem a Governança Ambiental Global, no sentido do conjunto de Estados voltados para a solução de um problema comum, e os Estados nacionais isoladamente.

A evolução do Direito Ambiental Global encontra sérios obstáculos na compatibilização dos interesses dos Estados, principais atores do Direito Internacional. Aliás, as dificuldades assinaladas também podem ser observadas no âmbito local. A própria legislação ambiental do Estado nacional tem encontrado dificuldades de consolidação tendo em vista os interesses econômicos que muitas vezes se sobrepujam aos interesses ambientais.

Ainda na esfera do combate ao aquecimento global e das mudanças climáticas destaca-se um exemplo relevante que demonstra a disparidade egoísta, em muitos casos, dos interesses envolvidos nessa questão. A promessa de campanha para a presidência dos Estados Unidos pelo candidato Donald Trump, promessa depois cumprida no exercício do mandato, no tocante à retirada dos Estados Unidos do acordo climático celebrado em Paris no ano de 2015 denota a prevalência dos interesses particulares norte-americanos em detrimento dos interesses coletivos globais.

O exemplo apresentado determina a possibilidade de a Democracia apresentar-se como importante limitador do desenvolvimento do Direito Ambiental. No caso em tela, limitando o Direito Ambiental no âmbito local, regional e também global. Reforça-se, também, que o exemplo apresentado trata de impactos tanto locais como globais.

De acordo com posicionamento de Ferrer (2002), tratando das limitações da Democracia para o desenvolvimento do Direito Ambiental:

As forças políticas sabem disso melhor do que ninguém e como seu objetivo legítimo é a conquista do poder, elas não proporão, muito menos executarão medidas que possam ser altamente impopulares e que as afastem de seu objetivo. Em países que são regidos por princípios democráticos, sujeitando seus governantes a eleições periódicas, não podem esperar adesões a projetos que envolvam sacrifícios para seus habitantes. Se, em algum assunto, seria necessário estabelecer consensos que a sub- 
traiam da luta eleitoral, seria este o caso (pp.28-29, tradução nossa) ${ }^{5}$.

As limitações impostas pela Democracia encontram eco em outra categoria importante e diretamente relacionada com a qualidade estatal: a Soberania.

É a Soberania que permite, por exemplo, o descumprimento de um acordo climático internacional ou a não adesão a acordos internacionais ambientais.

A Soberania determina a superioridade do poder estatal perante qualquer outro poder e essa supremacia permite aos Estados não se submeterem aos acordos internacionais caso os considerem contrários aos seus objetivos ou caso possam representar perigo à Soberania.

\section{Da Possibilidade de um Direito Ambiental Global}

Nos capítulos precedentes, tratou-se da necessidade de um Direito Ambiental Global tendo em vista o nível de degradação do meio ambiente global e dos impactos que advirão. Também foram abordadas as dificuldades que se apresentam para que um Direito Ambiental Global possa, de fato, ser implantado no planeta.

Apesar das dificuldades inerentes ao Direito Internacional, é possível identificar alguns movimentos que podem configurar os primeiros passos para um Direito Ambiental em escala planetária.

Um exemplo importante refere-se ao Protocolo de Montreal. O Protocolo de Montreal sobre Substâncias que Destroem a Camada de Ozônio foi assinado em 1987 por 197 países e determina obrigações específicas, em especial a progressiva redução da produção e consumo das substâncias que destroem a camada de ozônio até sua total eliminação.

Segundo Rei e Farias (2017), "objetivamente, o Protocolo de Montreal foi o primeiro tratado ambiental legalmente vinculante, firmado com o objetivo de proteger a camada de ozônio e eliminar a produção e o consumo de substâncias responsáveis por sua destruição" (p.166).

É importante frisar que os impactos econômicos determinados pelo Protocolo de Montreal eram substancialmente menores que aqueles pretendidos pelo Protocolo de Quioto, proposto uma década mais tarde, também objetivando proteger a atmosfera terrestre, mas, dessa vez, contra o acúmulo de gases de efeito estufa e suas consequências.

O Protocolo de Montreal é, de fato, um instrumento a ser comemorado não apenas pelo sucesso das metas apresentadas, mas, principalmente, pelo engajamento verificado. Com relação ao Protocolo de Quioto, entretanto, as dificuldades não superadas foram determinantes para o fracasso do instrumento.

A disparidade observada entre os dois instrumentos do Direito Internacional reflete as dificuldades enfrentadas pelos Estados na obtenção de resultados. Os exemplos assinalados dão conta da participação dos Estados nacionais no âmbito do Direito Internacional Público no sentido da promoção de ações para defesa do meio ambiente planetário, mas, ao mesmo tempo, refletem, na verdade, as dificuldades de atuação da Governança

\footnotetext{
5 Las fuerzas políticas conocen esto mejor que nadie y como su legítimo objetivo es la conquista del poder, no propondrán, ni mucho menos ejecutarán, medidas que pueden ser altamente impopulares y que les apartarían a ciencia cierta de su objetivo. En los países que se rigen por principios democráticos, sometidos sus gobernantes a periódicas elecciones, no pueden esperarse adhesiones a proyectos que supongan sacrificios para sus habitantes. Si en alguna materia sería necesario establecer consensos que la sustrajeran de la pugna electoral, sería esta.
} 
Ambiental Global na busca de soluções para problemas comuns.

Dado que os impactos relacionados com a matéria ambiental também não encontram limitações geográficas, a resolução de conflitos decorrentes pode trazer problemas relacionados com sua interpretação. Nesse sentido, Truilhé-Marengo (2017) considera que já há, na Europa, certa padronização nos procedimentos jurisdicionais para a solução de conflitos ambientais permitindo, no entendimento do autor, conjecturar a emergência de um Direito Ambiental Global: "É absolutamente essencial construir uma 'justiça global do meio ambiente', uma justiça capaz de lidar com litígios ambientais que são, na sua essência, transdisciplinar, transnacional, transgeracional e global" (p.78, tradução nossa) ${ }^{6}$.

O processo de construção de um Direito Ambiental Global passa, obrigatoriamente, pela participação e engajamento de diversos atores, para além dos Estados nacionais. Há uma crescente mobilização envolvendo os chamados atores não tradicionais do Direito Internacional que incluem os indivíduos, as empresas multinacionais, as organizações não governamentais, além do estabelecimento de redes ambientais transnacionais.

Nesse sentido, Balbino (2017) destaca:

A utilidade da participação social para construção do direito ambiental global é reconhecida ao trazer contornos reais ao conceito ora construído, qual seja, a proteção do meio ambiente e o gerenciamento dos recursos naturais, através de critérios e instrumentos já existentes e aplicados na prática ambiental (p.100).

A participação social promovida pelos atores não tradicionais do Direito Internacional pode se valer do sentimento de pertencimento a uma causa comum. Nesse sentido, o atual estágio do processo de globalização acaba atuando, paradoxalmente, como forte incentivo e motor propulsor de mudanças ${ }^{7}$. Talvez a principal das mudanças (já em andamento) seria a noção de cidadania planetária.

Segundo Grubba, Rodrigues e Wandersleben, (2012), "a cidadania planetária se manifesta em diferentes expressões: a) nossa humanidade comum; b) unidade na diversidade; c) nosso futuro comum; e d) nossa pátria comum" (p.8). São expressões que aprofundam a questão do pertencimento e, ao mesmo tempo, reforçam ensinamentos anteriores de Morin (1995): "a possibilidade de uma opinião pública planetária existe: por intermédio dos meios de comunicação, [...] há consciência em flashes de identidade humana, consciência em flashes de cidadania terrestre" (p.137).

Reforçando a emergência de uma cidadania planetária, "as últimas três décadas são marcadas pela emergência de uma opinião pública internacional, portadora de uma consciência planetária, cada vez mais interdependente e de fenômenos transnacionais que requerem uma abordagem planetária" (Miranda \& Fraga, 2017, p.10).

Com relação à atuação positiva da globalização no desenvolvimento do Direito Ambiental Global, Percival (2011) identifica três áreas principalmente afetadas:

6 Ell apparaît du coup absolument indispensable de construire une «justice globale de l'environnement», une justice qui soit apte à traiter du litige environnemental qui est par essence trans-disciplinaire, transnational, transgénérationel, global en définitive.

7 Para aprofundamento nas questões envolvendo a importância da participação dos atores não tradicionais e, particularmente, a atuação do sentimento de pertencimento nesse processo, ver Armada, C. A. S. (2013). As limitações impostas ao Estado Nacional contemporâneo e a emergência de uma sociedade civil global. (Dissertação de Mestrado) Programa de Pós-Graduação Stricto Sensu em Ciência Jurídica da Universidade do Vale do Itajaí - UNIVALI. Recuperado de https://siaiap39.univali.br/repositorio/handle/ repositorio/1990

Pensamiento Americano Vol. 12 - No. 24·2019 • Julio - Diciembre · Corporación Universitaria Americana · Barranquilla, Colombia • ISSN: 2027-2448 http://publicaciones.americana.edu.co/index.php/pensamientoamericano/index 
Primeiro, os países estão emprestando leis e inovações regulatórias uns dos outros para responder a problemas ambientais comuns. Embora este não seja um fenômeno completamente novo, está ocorrendo em um ritmo imprevisível. Em segundo lugar, as ações judiciais que buscam responsabilizar as empresas por danos ambientais causados fora de seus países de origem estão levantando novas questões para o propósito de tais litígios de responsabilidade transnacional e se as cortes tradicionais devem solicitar a execução de julgamentos estrangeiros. Em terceiro lugar, as organizações não-governamentais desempenham um papel importante na influência do comportamento corporativo promovendo maior divulgação e transparência informacional para mobilizar consumidores informados (p.579, tradução nossa) ${ }^{8}$.

A globalização permite a ocorrência de uma inversão interessante na atuação dos diferentes atores da Governança Global. Segundo Percival (2011), "a abordagem tradicional 'de cima para baixo' para a negociação de acordos internacionais multilaterais está dando lugar a uma variedade de iniciativas 'de baixo para cima' que muitas vezes envolvem maior participação de ONGs" (p.579, tradução nossa ${ }^{9}$. Como consequência direta desse processo tem-se a emergência do Direito Global.

Considerando as limitações de atuação tanto das iniciativas 'de baixo para cima' quan- to das iniciativas 'de cima para baixo', especificamente no que se refere à Governança Global para as mudanças climáticas, alguns autores defendem a possibilidade de uma governança multi-nível, no sentido de arranjos nos níveis regionais, nacionais e subnacionais, que se caracterizariam, principalmente, pela necessária ação descentralizada. (Peel, Godden y Keenan, 2012, p.6).

Também aliando a Governança Global com o Direito Ambiental Global, Kotzé (2014) pondera a necessidade de uma atuação cada vez mais multi-nível do Direito Ambiental Global e da Governança Global. Em adição, alerta para a utilização do termo global no seguinte sentido:

Torna-se assim possível empregar o termo 'global' para descrever toda uma gama de questões ambientais multi-níveis, recíprocas e interconectadas, níveis de governança e atores estatais e não estatais e suas muitas regras, que se manifestam em um espaço multi-nível (geográfico), temporal e causal que poderia ser descrito como uma massa global complexa e interligada (p.145, tradução nossa) ${ }^{10}$.

Tabau (2017, pp.65-66) destaca a transparência como uma das principais características do Direito Ambiental Global e assinala o marco determinado pelo Acordo de Paris neste quesito. A Governança Climática Global, segundo a autora, poderia ser pensada numa perspectiva de Direito Global, especialmente depois da adoção do Acordo de Paris.

8 First, countries increasingly are borrowing law and regulatory innovations from one another to respond to common environmental problems. Although this is not an entirely new phenomenon, it is occurring at an unprecedented pace. Second, lawsuits seeking to hold companies liable for environmental harm they have caused outside their home countries are raising new questions concerning the appropriate venue for such transnational liability litigation and the standards courts should apply for enforcement of foreign judgments. Third, nongovernmental organizations are playing an increasingly important role in influencing corporate behavior by promoting greater informational disclosure and transparency to mobilize informed consumers

9 The traditional "top-down" approach of negotiating multilateral international agreements is giving way to a variety of "bottom-up" initiatives that often involve greater participation by $\mathrm{NGOS}$

10 It thus becomes possible to employ the term 'global' to describe a whole range of multi-level, reciprocal and interconnected environmental issues, governance levels and state and non-state actors and their many rules, which manifest in a multi-level spatial (geographic), temporal and causal setting that could be described as a complex, intertwined global mass

Pensamiento Americano Vol. 12 - No. 24 • 2019 • Julio - Diciembre · Corporación Universitaria Americana · Barranquilla, Colombia • ISSN: 2027-2448 http://publicaciones.americana.edu.co/index.php/pensamientoamericano/index 
Os desafios são enormes e compatíveis com as consequências da inação dos atores da Governança Global. Nas palavras de Kotzé (2014), "a responsabilidade agora é dupla na medida em que exige uma responsabilidade para todo o sistema terrestre e, ao mesmo tempo, uma responsabilidade de agir para manter esse sistema" (p.155).

Os desafios não são apenas dos Estados nacionais em seus espaços territoriais ou da comunidade internacional no âmbito da Governança Global. Os desafios incluem a participação de todos os atores envolvidos na defesa do meio ambiente planetário e incluem uma sociedade civil global emergente através da participação cada vez maior das organizações não governamentais (ONGs) nacionais e transnacionais e do monitoramento que a rede mundial de computadores possibilita.

O crescimento quantitativo e qualitativo das organizações não governamentais tem contribuído para o desenvolvimento do Direito Ambiental e para uma conscientização relacionada com a defesa do meio ambiente do planeta.

Alinhando o incremento de organismos não estatais (ONGs) voltados para a defesa do meio ambiente e a participação efetiva do indivíduo na defesa da qualidade ambiental global, reforça-se o sentimento de pertencimento:

O sentimento de pertencimento à uma causa comum, aliado às possibilidades técnicas deste início do século XXI, estimula a participação transnacional e, como já afirmado, não está limitado às fronteiras dos Estados nacionais. Nesse sentido, uma participação global transnacional em questões de cunho planetário deixa de ser algo utópico. O sentimento de pertencimento não se esgota na causa abraçada pelo indivíduo. A relação existente entre os objetivos da associação e sua amplitude favorece o estabelecimento de uma sociedade civil mais ampla (Armada \& Pavan, 2012, p.1731).

A complexidade que caracteriza os tempos atuais estabelece, por um lado, contornos planetários e define o alcance dos níveis de degradação ambiental. Por outro lado, contudo, permite a urgência no estabelecimento de uma conscientização também global.

\section{Considerações Finais}

O Direito Ambiental Global, no sentido de regulações nacionais e internacionais que ultrapassem os entraves das fronteiras criadas pelo ser humano tem, na preservação do meio ambiente planetário, o sentido do cuidado com um bem comum maior, a própria continuidade da história do ser humano neste planeta.

A consolidação do Direito Ambiental Global passa, necessariamente, pela superação das dificuldades determinadas por duas categorias que caracterizam os Estados nacionais. A primeira delas, contemplando os Estados contemporâneos no que se refere à Democracia, e a segunda no que concerne à Soberania.

Apesar das dificuldades que se apresentam para a consolidação de um Direito Global versando sobre a temática ambiental, paulatinamente verifica-se uma confluência de ações voltadas para a preservação do meio ambiente planetário. A adesão de quase a totalidade dos países ao Acordo de Paris não é um exemplo isolado, uma vez que a adesão aos Objetivos do Desenvolvimento Sustentável também foi maciça, embora represente, claramente, uma alternativa de soft law no âmbito internacional. 
O movimento de constitucionalização do meio ambiente como um direito humano, por outro lado, reforça as possibilidades de implementação de um Direito Ambiental Global.

\section{Referencias}

Armada, C. A. S. (2013). As limitações impostas ao Estado Nacional contemporâneo e a emergência de uma sociedade civil global. (Dissertação de Mestrado) Programa de Pós-Graduação Stricto Sensu em Ciência Jurídica da Universidade do Vale do Itajaí UNIVALI. Recuperado de: https://siaiap39.univali.br/ repositorio/handle/repositorio/1990

Armada, C. A. S. \& Vieira, R. S. (2015). Geodireito global: alternativa de superação das limitações estatais. Justiça do Direito, 29(2). 736-

Armada, C. A. S. y Pavan, K. (2012). O papel das organizações não governamentais na evolução do direito ambiental e na emergência de uma sociedade civil global. Revista Eletrônica Direito e Política, 7(3). Recuperado de www.univali.br/direitoepolitica

Balbino, M. L. C. (2017). A participação social na construção do direito ambiental global. Revista de Direito Internacional. Brazilian Journal of International Law, 14(3). Recuperado de: https://www.publicacoesacademicas.uniceub.br/rdi/article/view/4978

Ferrer, G. R. (2002). La construcción del derecho ambiental. Revista Aranzadi de Derecho Ambiental, 1. Recuperado de: https://dda.ua.es/documentos/construccion_derecho_ambiental.pdf

Forst, R. (2002). Contexts of justice: political philosophy beyond liberalism and communitarianism. In A. Follesdal, y T. Pogge. (Eds.). Real World Justice: Studies in Global Justice (vol. 1). Springer, Dordrecht.

Grubba, L. S., Rodrigues, H. W. \& Wandersleben, M. (2012). Caminhos para uma cidadania planetária e Ambiental. Revista de Direito Internacional. Brazilian Journal of International Law, 9(3).

Hautereau-Boutonnet, M. (2017). Une illustration du droit global, la lex mercatoria climatique. Revista de Direito Internacional. Brazilian Journal of International Law, 14(3).

Kotzé, L. J. (2014). Rethinking Global Environmental Law and Governance in the Anthropocene. Journal of Energy \& Natural Resources Law, 32(2). 
Landa, R., Ávila, B. \& Hernández, M. 2010. Cambio Climático y Desarrollo Sustentable para América Latina y el Caribe. Conocer para Comunicar. British Council, PNUD México: Cátedra UNESCO-IMTA, FLACSO

Miranda, J. A. A. \& Fraga, M. N. (2017). Sociedade Global e Movimentos Sociais em Rede: Expansão da Democracia? Prim@ Facie, 16(31).

Morin, E. \& Kern, A. B. (1995). Terra-Pátria (Paulo Neves, Trad.). Porto Alegre: Sulina.

Nobre, C. (2008). Mudanças Climáticas Globais. In Encontro Nacional de Estudos Estratégicos (7: 2007: Brasília, DF). Anais do VII Encontro Nacional de Estudos Estratégicos. Brasília: Presidência da República, Gabinete de Segurança Institucional.

Peel, J., Godden, L. \& Keenan, R. (2012). Climate Change Law in an Era of Multi-Level Governance. Transnational Environmental Law, 1(2).

Percival, R. V. (2011). Global Law and the Environment. Washington Law Review, 86(49).

Rei, F. \& Farias, V. C. (2017). 30 anos do Protocolo de Montreal: Uma história de sucesso do Direito Ambiental Internacional. Revista de Direito Internacional. Brazilian Journal of International Law, 14(3).

Steffen, W, Richardson, K., Rockström, J., Cornell, S., Fetzer, I., Bennett, E., Biggs, R., Carpenter, S. \& Vries, W. (2015). Planetary boundaries: Guiding human development on a changing planet. Sciencie. Recuperado de: http://precaution.org/lib/steffen_planetary_ boundaries(incl_supplemental).150213.pdf

Ruschel, C. V. \& Portanova, R. (2015). Desenvolvimento e meio ambiente: que rumo o direito deve seguir? Revista Eletrônica Direito e Política, Programa de Pós-Graduação Stricto Sensu em Ciência Jurídica da UNIVALI, Itajaí, 10(1).

Staffen, M. R. (2016). Direito global: humanismo e direitos humanos. RMVD, Brasília, 10(1).

Stockholm Resilience Centre. (2018). The nine planetary boundaries. Recuperado de: http://mww.stockholmresilience.org/research/planetary-boundaries/ planetary-boundaries/about-the-research/the-ni- ne-planetary-boundaries.html

Tabau, A. (2017). Une gouvernance globale du climat par la transparence depuis l'Accord de Paris: le droit global de l'environnement comme solfège? Revista de Direito Internacional. Brazilian Journal of International Law, 74(3).

Truilhé-Marengo, E. (2017). La progressive harmonisation des règles du procès environnemental: manifestation de l'émergence d'un droit global? Revista de Direito Internacional. Brazilian Journal of International Law, 14(3).

Waeyenberge, A. V. (2017). Direito Global: Uma teoria adequada para se pensar o direito ambiental? Revista de Direito Internacional. Brazilian Journal of International Law, 14(3).
2019, Vol. 12(24) 117-129 @The Author(s) 2019 Reprints and permission: www.americana.edu.co https://www.coruniamericana.edu.co/publicaciones/ojs/index.php/pensamientoamericano/index 